\title{
From the Editors
}

With the third issue of De Ethica, we complete the first volume and the first year of the journal. When we started, we anticipated that there would be three phases that a journal must work its way through. First, a journal must go from being a mere idea to actually becoming a journal by putting together an issue. This was a process that required some effort, and an experience that consolidated the editorial team. In many ways, it was 'learning by doing', and the publication routines were fine-tuned along the way. In our case, this process was greatly facilitated by Linköping University Electronic Press, which handles the actual publishing for us. That, together with our Editor in Chief Brenda Almond's extensive experience and the financial support we were granted from the Swedish Research Council, enabled us to successfully navigate our way through the first phase.

A second phase that a new journal has to survive is the first couple of years of publishing, trying to establish a publication record and to earn a reputation as a promising journal. Having published three issues in 2014, we are on our way to prove ourselves as a reliable journal. De Ethica is still, as it should be, in this second phase.

Within a couple of years, we hope to move into the third phase of a scholarly journal. In this phase, the journal is an established academic outlet, with well-functioning routines and a steady stream of high-quality submissions. The challenge in this phase is to consolidate and to consistently improve the reputation and overall quality of the journal. Given the competition among academic journals, this is no doubt a formidable challenge, which will require considerable work - and perhaps even luck. Nevertheless that is what we aim for: to become an established journal known for its high quality, in terms of both content and publication process.

But we are not merely trying to establish De Ethica as a scholarly journal. We are also trying to build a Societas Ethica journal. ${ }^{1}$ This is perhaps not the most difficult task after all, De Ethica is the creation of Societas Ethica, and continues to be intimately linked to the society - but it is an important one. While remaining a journal that appeals to a wide scholarly audience, it should also reflect the values and diversity found in Societas Ethica, and it should be an attractive option for members to publish their work in. In the years to come, we hope to consolidate De Ethica not only as a high-quality journal, but as Societas Ethica's high-quality journal.

In the last issue of 2014 we offer three articles, all of which discuss topics that are important not only to fellow scholars, but to policy-makers as well as the general public. The first article, by William Simkulet, deals with questions related to free will and moral 
responsibility. Simkulet argues that the concepts of free will and moral responsibility are inexorably tied to our experiences of us as free and morally responsible agents. If true, Simkulet argues, then the theories of determinist compatibilists are incoherent.

The second article, by Norbert Campagna, examines the important ethical problem of climate migration and the state's duty to protect. Campagna argues that we have a human right not to have to migrate, and that the protection of such right implies that every state has a prima facie duty not to allow activities on its territory that, as a consequence, will force people to migrate.

The third article in this issue discusses bioethics and environmental ethics in general, and human enhancement technologies and sustainability in particular. Joan McGregor attempts to reunite the two general areas, and argues that when doing so, one will discover that many of the envisioned scenarios involving human enhancement fail in regard to our duties to future generations.

De Ethica and its editors would also like to use the occasion of this first complete volume to thank the scholars who have helped us by serving as reviewers. Our reviewers have helped to increase the quality of the submitted papers by their insightful and constructive comments. We wish to express our gratitude to David Alm, Ben Almassi, John Baird Callicott, Edward Beach, Gisela Bengtsson, Chiara Certomà, Susan Clayton, Göran Collste, Ashlee Cunsolo Willox, Oisín Deery, Göran Duus-Otterström, Carmel Finley, Carl-Henric Grenholm, Gösta Grönroos, Alexander Guerrero, Hille Haker, Clive Hamilton, Paul Harris, Bernard Harrison, Rebekah Humphreys, Thomas Kazen, Elaine Kelly, Damien Keown, Yehuda Klein, Tom Koch, Aaron Maltais, Thomas Mautner, Anders Melin, Theresa Morris, David Morrow, John Nolt, Anders Nordgren, Michael Northcott, Carlos Patarroyo, Anthony Raymond, Dominic Roser, Ruth Sandberg, Jens Schlieter, Sandra Shapsay, Fernando Suarez, Gotlind Ulshöfer, Peter Vallentyne, and Jörgen Ödalen.

Publication made possible by generous support from the Swedish Research Council. 